\title{
A SITUAÇÃO DA MÍDIA IMPRESSA BRASILEIRA E OS IMPACTOS DA ERA DIGITAL
}

\author{
THE SITUATION OF PRINTED MEDIA BRAZILIAN AND THE \\ IMPACTS OF DIGITAL AGE
}

DOI: http//dx.doi.org/10.15448/2178-3748.2017.2.23171

\author{
Patrícia Trindade Trizotti \\ Doutora em História (Unesp/Assis) \\ Professora colaboradora na Universidade Estadual do Paraná (Campus Paranaguá) \\ patytrizotti@yahoo.com.br
}

\begin{abstract}
RESUMO: Sabe-se do papel fundamental que a imprensa escrita exerceu nas sociedades ao longo do tempo e como foi responsável não por apenas divulgar os fatos ocorridos, mas também por ser um agente histórico capaz de intervir nos rumos de diversas situações fossem de caráter político ou cultural. Mesmo diante do surgimento de novos meios de comunicação que diversificaram a transmissão das opiniões e da notícia como foi o caso do rádio e da televisão, os jornais e revistas continuaram a manter seu status quo. No entanto, nas últimas décadas, esses tipos de impressos estão perdendo cada vez mais espaço frente ao advento do meio digital ao qual aliado a crises econômicas, fazem a mídia impressa não ser mais alvo do interesse popular. Assim, o presente artigo tem por finalidade discutir a importância da imprensa escrita e fazer um balanço acerca dos problemas financeiros e de circulação que alguns jornais têm enfrentado não só em nível internacional, mas também levando em consideração a imprensa brasileira. Também se procurou elencar algumas tentativas por parte de periódicos em encontrar soluções para evitar o débâcle, sejam reestruturando seus perfis ou se rendendo e migrando de vez para o meio eletrônico.
\end{abstract}

PALAVRAS-CHAVE: Imprensa. Era digital. Crise dos jornais.

ABSTRACT: It is known in the important role the press played in societies over time and how it was responsible not for only disclosing the events, but also as a historical agent capable of intervening in the course of several situations were of a political nature or cultural. Even before the emergence of new media that have diversified the transmission of opinions and news as was the case of radio and television, newspapers and magazines continued to maintain the status quo. However, in recent decades, these types of print are losing more and more ground against the advent of digital media, which coupled with economic crises, make the print media no longer target the popular interest. Thus, this article aims to discuss the importance of the written press and take stock on the financial and circulation problems that some newspapers have faced not only internationally, but also taking into account the Brazilian press. Also we tried to list some attempts by newspapers to find solutions to avoid the debacle, are restructuring their profiles or surrendering and migrating from time to electronic media.

KEYWORDS: Press. Digital age. The newspaper crisis.

Dentre as inúmeras fontes históricas existentes, a imprensa tem sido largamente utilizada nos últimos anos pelos pesquisadores de diversas áreas. É notória a quantidade de trabalhos apresentados em congressos, de artigos publicados nas revistas de História, bem 
como, no grande contingente de dissertações e teses defendidas todos os anos nos programas de pós-graduação do país. O interesse pelos periódicos de certa forma é ainda um pouco recente, visto que até a década de 1970, a preocupação era viabilizar apenas a História da Imprensa e não esta como fonte para a escrita da História. Quando se passou a utilizar os periódicos como fonte, seu uso era, sobretudo, instrumental e tomava as folhas como receptáculos de informações que poderiam ser acionadas de acordo com a vontade do pesquisador, ainda que muitos continuassem desconfiados de sua eficácia (LUCA, 2006, p.116)

No entanto, com a ascensão da terceira geração da escola dos Annales, a prática historiográfica passou por mudanças significativas, não só nas temáticas, mas também na busca por novos documentos e por uma renovação do olhar sobre os que já existiam. Nesse contexto, o jornal acabou tornando-se o próprio objeto da pesquisa e importantes trabalhos vieram a público como o de Armando Contier (1973), Maria Helena Capelato e Maria Ligia Prado (1974) e a de Maria Nazareth Ferreira (1976). ${ }^{1}$ Cabe destacar que, nesse bojo, os trabalhos que buscavam fazer a história do movimento operário encontraram na imprensa um campo profícuo, assim como aqueles que tinham por intenção investigar o processo de urbanização das capitais brasileiras nos anos iniciais do século XX (LUCA, 2006, p. 117-120).

À medida que os anos passaram, não só os jornais passaram a figurar como importante fonte para se compreender o ritmo de determinadas épocas, mas uma nova gama de impressos passou a ser analisada pelos pesquisadores, caso das revistas, folhetos, almanaques e histórias em quadrinhos. Outros meios de difusão além do papel passaram a ser foco de interesse, como a época de ouro do rádio que, ao lado da mídia televisiva tornou-se também objeto da investigação histórica. No entanto, cabe destacar, que a respeito do uso desse tipo de fonte, Marcos Napolitano ressaltou que os historiadores no Brasil ainda não descobriram inteiramente suas possibilidades de análise, já que o material visual produzido pertence às emissoras que por sua vez restringem seu acesso (NAPOLITANO, 2006, p. 235-289).

Assim, pode-se imaginar que a chegada de diversos aparelhos modernos e as transformações técnicas ocorridas no Brasil, entre o final do século XIX e o início do XX, alteraram comportamentos e suas formas de percepção na sociedade da época, conforme relatou Flora Sussekind. O posicionamento que Olavo Bilac, Godofredo Rangel, João do Rio e Lima Barreto tiveram não só em relação às transformações da imprensa, mas a outros artefatos que

\footnotetext{
1. Os títulos dos trabalhos citados foram respectivamente Imprensa e ideologia em São Paulo, O pensamento liberal de 'O Estado de São Paulo' (1927-1933), O pensamento liberal do jornal O Estado de S. Paulo (19321937) e Imprensa e Sociedade: O trabalhador gráfico.
} 
passaram a incorporar o cotidiano como o fonógrafo, foi assinalado pela pesquisadora. Enquanto os textos de João do Rio estavam check to check com os novos meios de reprodução, ou seja, atribuía a estes contornos sedutores, Bilac que teve quase a totalidade de sua produção veiculada nos jornais, apontava estes como prováveis responsáveis por um futuro afastamento dos homens das letras das redações dos periódicos (SUSSEKIND, 1987, p. 19-21).

O temor de encarar a máquina de escrever e a datilografia dos textos ainda permanecia para alguns escritores, mesmo passado anos de sua incorporação no Brasil. Em carta de 1925, Mario de Andrade comunicou a Manuel Bandeira a aquisição, mediante prestações, de uma máquina e da conquista gradual de intimidade com seus mecanismos:

Comunico que comprei esta máquina. Se você estivesse aqui era um abraço pela certa, tanto que estou contente. Já se sabe: pelo processo amável das prestações. Engraçado, por enquanto me sinto todo atrapalhado de escrever diretamente por ela. A ideia foge com o barulhinho, me assusto, perdi o contato com a ideia. Isso: perdi o contato com ela. Não apalpo ela. Mas isso passa logo, tenho a certeza, e agora que você vai receber cartas bonitas de mim (apud SUSSEKIND, 1987, p. 146).

O mesmo sentimento de estranhamento aconteceu quando as máquinas de escrever foram substituídas por computadores nas redações dos jornais. A incorporação desse suporte mudou não só o modo de se conceber a edição dos impressos, mas também o próprio ambiente de trabalho em que foram instalados. O barulho antes produzido pela máquina de escrever foi engolido pelo silêncio dos computadores, que tornaram a redação mais limpa, como atestou em 1991, o jornalista Darci Demétrio ao relatar que os papéis arrancados do cabeçote das máquinas e, costumeiramente, espalhados pelo piso, já não se encontravam mais nesse. O papel continuava a ser utilizado apenas por repórteres que saiam às ruas e pelos diagramadores, que nem de régua e compasso precisavam mais, visto que a nova máquina realizaria os cálculos a partir de então (SILVA, 2010).

A partir de 1980, o Brasil passou a utilizar computadores, uma nova forma de organização que passou aos poucos a integrar a vida dos indivíduos. Na década posterior, com o advento desse suporte, surgiu a internet, que facilitou o trabalho dos integrantes dos jornais, ao permitir a troca instantânea de informações e possibilitar que se fizessem edições cada vez mais elaboradas. Esta também se tornou objeto de discussão no meio acadêmico e embora o debate a respeito de seu uso seja muito atrativo, o que interessa aqui é perceber e analisar como a mídia impressa e particularmente os jornais tem convivido e lidado com o mundo digital. 
Sabe-se que tal sistema cada vez mais permite que notícias e imagens sejam difundidas de forma cada vez mais rápida e em uma escala menor de tempo.

Em relação ao impacto que tais inovações podem causar, existem opiniões divergentes. O filósofo Pierre Levi percebeu nos novos recursos um modo de se realizar uma profunda renovação do laço social, no sentido de uma maior fraternidade e da resolução dos problemas com os quais a humanidade ainda se debate (LÉVY, 2000, p. 13). Para Levi, necessitava-se descobrir ou inventar um modo para que a informação fosse distribuída e coordenada por toda parte, de forma que todos compartilhassem seus conhecimentos e formassem assim a chamada inteligência coletiva. A princípio pode parecer que todos comungam do pensamento de que as invenções e o aprimoramento das técnicas só tragam benefícios para a sociedade, mas nem todos viram com entusiasmo as mudanças ocorridas ao longo das décadas.

A posição de Levi é otimista, se quisermos comparar sua visão com de outros intelectuais que também presenciaram o desenvolvimento de novas tecnologias e seu impacto na sociedade. A pensadora alemã Hannah Arendt, falecida em 1975, por exemplo, embora não seja contemporânea de Levi e óbvio, não teve contato com o mundo digital, não via com bons olhos na sua época o avanço da modernidade e de seus artefatos. Hannah desacreditava que os homens em tempos futuros pudessem viver em uma democracia em que todos seriam iguais e viveriam em harmonia. Para a filósofa - que antes se considerava mais uma pessoa envolvida em política do que outra coisa - os homens não podiam ser cidadãos do mundo como o eram de seus países e nem homens sociais poderiam ser donos coletivos como os homens que tem um lar e uma família e são donos de uma propriedade privada. A ascensão da sociedade teria trazido consigo o declínio simultâneo das esferas públicas e privadas e o eclipse de um mundo comum (ARENDT, 2001, p. 269). Um dos autores que poderiam ser acionados para balancear essa dicotomia pró e contra tecnologia e seus efeitos na sociedade, poderia ser o francês Paul Virilio. Embora considere a evolução pela qual o mundo passou desde a invenção do motor à vapor - um dos grandes precursores da modernidade segundo este - era necessário refletir sobre como controlar a técnica para que não se tenha problemas no futuro com seu desenvolvimento.

Em texto escrito por Virilio na década de 1980, nota-se a tentativa de demonstrar como a tecnologia utilizada no cotidiano, por exemplo, foi derivada daquelas inventadas e aprimoradas na época de guerra, o que leva a se imaginar que se por um lado o conflito é destrutivo, por outro lado acaba por trazer benefícios de um modo geral. Tal pensamento fica claro quando se considera que o cinema, em vários momentos da história das guerras, serviu ditadores como Adolf Hitler, Benito Mussolini e mesmo políticos como Winston Churchill que 
utilizavam os filmes como armas de combate, além daquelas já existentes nas trincheiras. Segundo o filósofo, um dos instrumentos que serviu ao propósito foi a propaganda e nesse sentido caberia destaque o trabalho realizado pelo ex-jornalista Joseph Goebbels ao favorecer a ascensão de Hitler através dos mais diversos métodos. Depois de se tornar chefe de propaganda hitlerista, Goebbels enviou cerca de cinqüenta mil discos a todos os lares alemães que possuíssem fonógrafo e impôs aos diretores de salas de cinema, a projeção de curtasmetragens cujo conteúdo era profundamente ideológico (VIRILIO, 1984, p. 44). Assim, apesar desse tipo de uso do cinema e dos discos, sua indústria conseguiu progredir e se aprimorar para o lazer do público.

Deste modo, ao se levar em consideração a ideia de qual seria atualmente um dos ramos de comunicação mais afetados pelo avanço dos meios tecnológicos, parece fundamental discutir um pouco a respeito sobre a questão dos jornais impressos e sua relação com a chamada era digital e, a partir daí, refletir sobre os lados positivos e negativos da questão. Em primeiro lugar não se pode negar que a evolução da informática e das redes eletrônicas possibilitou a ampliação da informação no cotidiano das pessoas ao permitir a aceleração do tempo, o encurtamento de espaços, com o quase contato instantâneo com pessoas e fatos que estão a quilômetros de distância.

Em termos de pesquisa historiográfica o acesso a esse tipo de fonte ficou mais fácil, pois os avanços tecnológicos permitiram que se digitalizassem materiais e os disponibilizassem na web, onde já é possível ler coleções inteiras de jornais e revistas. Tal prática facilitou o trabalho de pesquisadores que na possibilidade de estarem fisicamente afastados dos acervos que abrigam seu objeto de interesse, podem acessar o conteúdo mais facilmente de suas casas. Além disso, a prática viabilizou ainda o cruzamento de dados, bem como forneceu pistas para a busca de determinadas informações, já que muitas plataformas permitem que seja feito o rastreamento da temática a partir de palavras-chave.

No entanto, não se pode esquecer que essas coleções só se encontram disponíveis porque em algum momento existiram em papel. Em um estudo realizado pela Pew Research Center para a 12a edição do State of The News Media 2015 sobre a mídia nos Estados Unidos, 56\% dos leitores no país afirmaram que a mídia impressa continuava sendo sua plataforma exclusiva de informação. Entretanto, a pesquisa também apontou o crescente acesso digital por meio de tablets e celulares, o que atesta que o advento de um novo estilo de vida, no qual as pessoas buscam praticidade e celeridade (O ESTADO DE S. PAULO, 2015, p.3). 
Justamente tal crescimento do interesse pela internet como suporte passou a ser um grande problema para os donos de jornais impressos. Nos últimos tempos, a pauta do debate passou a ser o fim (ou não) do papel numa sociedade cada vez mais cibernética. O professor da Universidade Federal Fluminense, Denis de Moraes, em entrevista concedida ao jornal argentino Página/12, apontou ainda que as quedas nas tiragens demonstram uma crise no chamado quarto poder, que não teria mais a possibilidade de ser um contrapeso dos outros poderes e a dificuldade dos grupos empresariais de ampliar suas bases de audiência (ARUGUETE, 2014).

Diante dessa discussão, os primeiros a enfrentarem o problema foram os periódicos norte-americanos, sobretudo com a deflagração da crise econômica mundial iniciada em 2008, que inquietou o mundo jornalístico. Sabe-se que em momentos difíceis, o setor de publicidade dos jornais é o primeiro a sentir seus efeitos. A queda nas vendas em ramos como mercado imobiliário e bens de consumo - que são o principal alvo de interesse dos consumidores desacelera a procura por anúncios e logo, passa a afetar a receita do jornal. Até a última década do século XIX, quem ajudava a sustentar em quase sua totalidade as despesas do jornal eram os assinantes com a renda obtida através da venda de subscrições. Mas no momento em que os periódicos passaram a se transformar em empresas, a arrecadação gerada pela publicidade passou a ter forte peso nos lucros.

Além disso, em meio ao alcance gerado pela internet começou-se a se perceber como os anunciantes digitais passaram a ser um poderoso concorrente para as folhas, já que os produtos são oferecidos de forma ágil e com grande ênfase nas redes sociais. Desde 2006, os sites que consistem em se apresentar como ferramentas de busca já inquietavam os proprietários dos jornais, tanto que se iniciou uma campanha contra esses que unia a Associação Mundial de Jornais, a Associação Internacional de Editoras, a Federação Europeia de Editoras de Revistas e a Agência France Presse, entre outras organizações. Estas associações repudiavam e acusavam sítios eletrônicos de explorarem injustamente seu conteúdo. A reclamação consistia no fato de que serviços como o Google News se utilizavam dos títulos e de pelo menos um parágrafo das notícias em sua página, o que fazia com que os leitores se contentassem apenas em "passar os olhos" pelas manchetes principais agrupadas nos sítios de busca (OBSERVATÓRIO DA IMPRENSA, 2006). Percebe-se assim, que já há alguns anos, se previa que a relação entre esses diversos grupos não seria fácil e geraria vários desentendimentos, além de demanda para o estabelecimento de novas regras e uso de copyright. 
Um dos primeiros casos que demonstrava o início da crise pela qual a imprensa escrita passaria a enfrentar foi consubstanciado na atitude do grupo Tribune Company. Editor de dois jornais importantes dos Estados Unidos - o Los Angeles Time e o Chicago Tribune - a empresa entrou com pedido de falência no final do ano de 2008. Na mesma época, o Wall Street Journal, informou aos seus leitores que a revista Newsweek, integrante do grupo Washington Post, diminuiria de formato e cortaria entre 500 mil e um milhão dos 2,6 milhões de exemplares que publica semanalmente (CARTA CAPITAL, 2008a). ${ }^{2}$ Já o centenário Rocky Mountain News, da cidade de Denver, Estado do Colorado (EUA), após cento e cinquenta anos de existência fechou as portas em fevereiro de 2009 (CARTA CAPITAL, 2009a).

Outros periódicos impressos norte-americanos, a fim de evitar o debacle provocado também pela baixa na publicidade e nas aquisições do jornal, resolveram se render a mídia eletrônica e criaram opções para enfrentar a situação. O Christian Science Monitor, jornal de circulação nacional, decidiu se transformar em uma publicação on-line e ao mesmo tempo editar o impresso numa versão menor e semanal ao custo de 90 dólares a assinatura, diferente dos 220 que cobrava em 2008, época do anúncio (CARTA CAPITAL, 2008b). Já o Pasadena Now, folha local de Los Angeles, criou polêmica ao abandonar a versão tradicional, demitir seu corpo editorial e contratar jornalistas de Bangalore na Índia, para a versão digital do jornal, pois os indianos seriam mão-de-obra barata, pois recebem apenas 7,50 dólares a cada 1000 palavras e podem enviar sua colaboração por e-mail (CARTA CAPITAL, 2008c).

Assim, os problemas financeiros enfrentados levam a um número preocupante de demissões. O matutino San José Mercury decidiu em 2005 demitir 14\% de seus jornalistas para compensar a queda da publicidade. Mas a decisão de despedir funcionários para cortar custos pode gerar outro problema: o padrão do jornal poderá ser afetado e a qualidade do que antes se produzia não ser a mesma, o que consequentemente vai provocar o desinteresse dos leitores. $\mathrm{O}$ Philadelfia Inquirer que também reduziu na época $15 \%$ de seu pessoal admitiu que a atitude gerava um círculo vicioso que muitas vezes afundava mais ainda o jornal do que salvava (CASTILHO, 2005).

Alguns jornais norte-americanos resolveram tentar manter as duas versões, impressa e digital, mas passaram a cobrar pelo acesso como foi o caso do magnata Rupert Murdoch, cujo controle abrange cerca de cem jornais e dezenas de canais de TV no mundo inteiro. Após a queda das receitas publicitárias em agosto de 2009, o empresário decidiu que em breve seus

\footnotetext{
${ }^{2}$ Os dados acerca dos periódicos americanos foram extraídos da coluna Ideias Tecnologia, de Felipe Marra Mendonça, publicada semanalmente na revista Carta Capital.
} 
títulos, entre os quais a revista Times e o tablóide The Sun, cobrariam pelo conteúdo disponível na Web. Alguns jornalistas o criticaram na época, outros apontaram a atitude com uma saída estratégica para a constante migração dos anunciantes da edição impressa para a internet (CARTA CAPITAL, 2009b). No entanto, o resultado não foi dos melhores, visto que se testou a proposta no site londrino de Times e constatou-se que dos milhares de visitantes diários do site, apenas 15 mil aceitaram pagar pelo acesso, o que significa que Murdoch perdeu 98,8\% dos internautas que passavam pelo site todos dos dias (CARTA CAPITAL, 2010).

Em relação ao Brasil, um dos primeiros a encerrar as atividades foi a Gazeta Mercantil (2009), título criado na década de 1920, mediante uma mistura de problemas econômicos e desentendimentos em sua administração. Em agosto de 2010, a notícia de que o centenário Jornal do Brasil deixaria de circular no formato impresso e sua edição seria exclusivamente on-line surpreendeu o público. Na época, o periódico havia acumulado uma dívida que chegava a casa dos 800 milhões de reais. Para amenizar o impacto do comunicado, os responsáveis pelo jornal tentaram usar como justificativa a questão ecológica, para explicar o fim de seu exemplar nas bancas, ressaltando que para apenas uma única edição de domingo do JB eram necessárias duzentas árvores, que ocupavam 40 mil metros quadrados de florestas. A versão digital preservaria assim significativamente o meio ambiente segundo tais cálculos. Mais ficou claro naquele momento, que do mesmo modo que algumas folhas norte-americanas migraram para a internet por conta dos prejuízos financeiros, o caso do Jornal do Brasil não era diferente.

Alguns meses depois, era o jornal $O$ Estado do Paraná que anunciava que também continuaria apenas com sua versão digital confirmando os rumores que já corriam no mercado. Apesar de ser mais jovem do que o Jornal do Brasil, contabilizando 59 anos de existência quando comunicou a mudança em 2011, o fato é que a crise começava a se espalhar para outras regiões além do eixo Rio-São Paulo. Na mesma situação, O Diário Popular, que demitiu 30 funcionários de uma só vez e o Hora H News, ambos pertencentes ao mesmo estado paranaense, também decretaram seu fim. Em 2012, o Diário do Povo, jornal que circulava a mais de cem anos em Campinas, no interior de São Paulo, também pôs fim a sua história impressa e tinha planos de manter a publicação apenas na internet. O Grupo RAC (Rede Anhanguera de Comunicação), administrador do periódico afirmou que os investimentos seriam concentrados em outros jornais de seu portfólio. Mas o jornal acabou sendo incorporado a outro título da empresa, o Correio Popular, que possuía versão digital além da impressa.

Ainda no mesmo ano foi a vez do Jornal da Tarde informar aos leitores o fim de sua circulação. Entretanto, diferente de outros, não haveria continuidade de sua edição na internet. 
Na última capa, datada de 31 de outubro, se apresentou como imagem de fundo, uma vista noturna de prédios com o Edifício Copan à frente, o jornal dessa forma se despedia: "Obrigado, São Paulo" e concluía "Termina hoje a história de 46 anos do JT, um jornal que nasceu para ser diferente e fez de sua cidade sua inspiração e do paulistano, seu parceiro.” Na ocasião, o Grupo Estado alegou que o encerramento das atividades do JT aconteceria por uma questão estratégica, já que a empresa gostaria de se concentrar em seu principal título, no caso O Estado de S. Paulo, e investir numa plataforma digital robusta para esse que concentrava boa parte da publicidade.

Entre 2014 e 2015, mais três títulos sucumbiram à crise do papel no mundo atual: Diário do Comércio, O Sul e mais recentemente Brasil Econômico. Os dois primeiros migraram para a internet, sendo o Diário uma publicação sustentada pela Associação Comercial de São Paulo e $O S u l$, jornal que circulava na região metropolitana de Porto Alegre. Quanto ao último, sua história no país era recente, visto ter sido criado em 2009, mas foi perdendo relevância até deixar de se tornar um projeto interessante para seus fundadores. Por fim, na lista de publicações que foram encerradas, não se pode esquecer que 2015 foi o ano em que a Editora Abril anunciou o encerramento da revista Capricho na versão impressa e a permanência do exemplar exclusivamente on-line, o que demonstra que não foram só os jornais que foram atingidos pela crise.

Criada na década de 1950, a revista foi pioneira entre as publicações voltadas para o público feminino e mesmo ao fazer mudanças gráficas e editoriais ao longo de sua trajetória a fim de reorganizar periodicidade, formato e conteúdo, nunca deixou de circular. Inclusive no decorrer da década de 1990, a Abril licenciou a marca Capricho que deu origens a uma série de produtos como perfumes, material escolar, maquiagens, bolsas, roupas etc. $\mathrm{O}$ fim da revista faz parte de uma reestruturação que a Editora Abril iniciou em junho de 2015, que também transferiu a revista Placar, Tititi, Contigo, AnaMaria, entre outras, para Editora Caras e pretendia trabalhar com os conceitos de native advertising e content marketing. ${ }^{3}$

Nessa mesma esteira, no fim do mesmo ano de 2015, foi a vez de a Abril divulgar o fim dos licenciamentos das versões brasileiras de Playboy que já estava em circulação há 40 anos, além de Men's Health e Women's Health. A justificativa também recaiu sobre direcionar seus esforços e investimentos para determinadas publicações de modo a atender as necessidades do

\footnotetext{
${ }^{3} \mathrm{O}$ conceito de native advertising se constitui na ideia de publicar postagens variadas identificadas como publicidade, no meio do conteúdo de um site ou de redes sociais. Estas são pagas e tem o mesmo layout da plataforma na qual estão inseridas. Já o content marketing é a criação e distribuição de conteúdo em vários formatos para atrair e "educar" consumidores, a fim de gerar fidelização por parte dos clientes durante a entrega de informações valiosas pelas empresas.
} 
leitor e do mercado. ${ }^{4}$ Um mês antes de a editora anunciar a decisão, a administração da Playboy norte- americana, havia decidido parar de publicar fotografias de mulheres nuas, por conta da forte concorrência com sites pornográficos que haviam prejudicado a receita da empresa em relação a esse tipo de revista. O pronunciamento de ambos os grupos, sobretudo da Editora Abril, surpreendeu o ramo jornalístico como um todo, visto que a empresa sempre foi considerada umas das mais fortes do segmento que liderou a inclusão e diversificação de vários impressos ao longo de décadas.

Em meio aos anúncios de encerramento, uma questão importante levantada diante de tal cenário é o crescente acesso do cidadão a informação, sem passar, como antes era via de regra, pelos meios tradicionais de difusão como aponta Ignacio Ramonet:

O novo dispositivo tecnológico faz com que cada cidadão deixe de ser o receptor da informação - acabando assim, com um modelo que foi norma durante muito tempo, desde o advento dos meios de massa. Nunca na história das mídias, os cidadãos contribuíram tanto para a informação. Hoje, quando um jornalista publica um texto on-line, ele pode ser contestado, completado ou debatido, sobre muitos assuntos, por um enxame de internautas tão ou mais qualificados que o autor. Assistimos, portanto, a um enriquecimento da informação graças aos "neojornalistas", que eu chamo de "amadoresprofissionais.” (MORAES, 2013)

Assim, o problema enfrentado passa por várias esferas que vão desde uma crise interna na administração dos jornais à diminuição da publicidade, passando pelo novo papel desempenhado pelos leitores. Uma das soluções encontradas pelas corporações passou a ser cobrança do conteúdo que migrou para a internet. Numa pesquisa simples a respeito dos valores cobrados pelos jornais e revistas brasileiros de forma total ou parcial, um jornal exclusivamente digital, como o Jornal do Brasil, custaria R $\$ 9,90$ por mês ao usuário. Este poderia acessar sua edição de qualquer lugar e quantas vezes quisesse. ${ }^{5}$ Já Capricho Week, novo título incorporado na fase atual, destaca em sua página que o preço total de uma assinatura "normal" por um ano seria de $\mathrm{R} \$ 130,00$ mas a opção pelo pagamento à vista ou parcelado gera desconto no valor e respectivamente o interessado pagaria $R \$ 82,80$ ou $R \$ 92,00$. Não fica claro, o que seria a assinatura normal que se faz referência, mas talvez seja uma comparação com a versão impressa, que apesar de não ser mais distribuída, serve de parâmetro para o/a cliente perceber as vantagens da revista na internet.

\footnotetext{
${ }^{4}$ Cabe destacar que outros setores além da imprensa sofrem as consequências de um mundo mais interessado pela internet e por formas rápidas de acesso, caso das gravadoras musicais e das locadoras de vídeos que praticamente desapareceram das cidades e até mesmo a indústria de filmes pornográficos.
}

${ }^{5}$ Valores referentes a fevereiro de 2016.

Oficina do Historiador, Porto Alegre, EDIPUCRS, v. 10, n. 2, jul./dez. 2017, 
Dois dos grandes jornais que circulam atualmente como $O$ Estado de S. Paulo, fundado em 1875 e a Folha de S. Paulo, originada da junção da Folha da Noite (1921), Folha da Manhã (1925) e Folha da Tarde (1949), possuem as versões impressa e digital assim como alguns periódicos norte-americanos. Foi a solução das duas empresas mediante a percepção da busca pela internet por parte dos leitores. A oferta de assinatura de ambos os jornais é bem variada, com possibilidades para o gosto de cada tipo de consumidor. Os que optam por assinar o Estado podem escolher apenas a versão digital, o jornal impresso diariamente ou só em alguns dias, as duas modalidades ao mesmo tempo ou mesmo pagar apenas pelo acesso ao portal do Estadão. Os preços para todas essas variedades de oferecimento estão elencadas numa página da web dinâmica e ficam entre $\mathrm{R} \$ 9,90$ até $\mathrm{R} \$ 89,90$ mensais, com direitos a brindes e descontos em novas aquisições. $\mathrm{O}$ grupo Folha possui cinco tipos de propostas, uma a menos que seu concorrente.

No entanto, a fim de conquistar o leitor, se oferece gratuitamente o jornal Folha de $S$. Paulo por 15 dias e a partir do décimo dia de entrega, caso o usuário não entre em contato com a central de atendimento, a cobrança da assinatura será efetivada, já que para participar da promoção é preciso fornecer alguns dados pessoais. Diferente da página do Grupo Estado, os preços não estão facilmente identificáveis em um primeiro momento, mas ficam em torno de $\mathrm{R} \$ 47,90$ a $\mathrm{R} \$ 178,00 .{ }^{6}$ Mas sem dúvida a grande contribuição de ambos os grupos - Folha e Estadão - ao lançar seus exemplares na internet foi a incorporação dos jornais já publicados por ambos ao longo de sua história, disponibilizando assim um vasto acervo que permite ao usuário fazer consultas por datas, palavras-chaves e até mesmo salvar páginas consultadas em computadores pessoais, caso da plataforma de $O$ Estado de S. Paulo.

Medidas à parte para cativar o público, a sobrevivência dos jornais foi o tema dos debates ocorridos no X Congresso da Abraji (Associação Brasileira de Jornalismo Investigativo) realizado em julho de 2015. Em uma das mesas se reuniram para a discussão Ascânio Seleme, diretor de redação de $O$ Globo, Ricardo Gandour, diretor de conteúdo do grupo Estado, e Vinícius Mota, secretário de redação da Folha de S. Paulo. O primeiro elencou uma série de seis medidas adotadas por seu jornal para enfrentar a crise, entre as quais estão: aumento da produtividade, planejamento antecipado das coberturas jornalísticas especiais, conhecimento do perfil do leitor, aprofundamento das métricas, reuniões diárias com os editores e domínio da tecnologia (PIMENTA, 2015).

\footnotetext{
${ }^{6}$ Só foram considerados os valores mínimos e máximos de pagamentos mensais nas páginas de ambos os jornais, independente da periodicidade proposta.
} 
Cabe destacar que nesse sentido, desde 2014 uma grande tela foi alocada nas redações dos jornais e exibe em tempo real as métricas registradas pelo software Google Analytics, ou seja, o dispositivo monitora o trajeto dos usuários nos sites cadastrados e organiza dados como quais são as páginas mais e menos visitadas, o tempo de permanência em cada uma etc. Como sugere a jornalista Lívia Vieira, até que ponto acompanhar o ritmo desses números pode influenciar a pauta dos jornais, na qual a prioridade seria da notícia mais acessada, independente de sua qualidade e relevância pública? (VIEIRA, 2014, p. 214).

Outras soluções que estão sendo cotadas pelos proprietários dos impressos é o fortalecimento do jornalismo investigativo, baseados no fato de que a notícia rápida, sobretudo, aquela vinculada em certos sites e propagada pelas redes sociais, não leva em consideração a verificação das informações, o que muitas vezes permitem que certos rumores ganhem status de verdade. A ideia é enfatizar que os periódicos impressos têm a responsabilidade de averiguar evidências, confrontar depoimentos e legitimar a história com provas concretas. Outra possibilidade a ser trabalhada é estabelecer uma espécie de colaboração com as redes sociais. Nesse sentido, o Facebook consultou os principais jornais brasileiros como Folha de S. Paulo, O Globo e $O$ Estado de S. Paulo em junho de 2015, a fim de saber sobre a possibilidade de uma possível parceria na publicação de notícias diretamente por essa rede social. Mas os jornais ainda estão inquietos sobre o modo como se daria esse sistema, já que existe a preocupação de que a plataforma ganhe uma importância exagerada (FOLHA DE S. PAULO, 2015).

As versões on-line de jornais e revistas levantam ainda outra questão importante que preocupa os pesquisadores da imprensa que é a efemeridade das páginas. Esse problema não é exclusivo dos jornais, mas de toda a rede digital, visto que o suporte se concentra em um emaranhado de fios, placas de armazenamento e base de dados. Lynne Brindley, gestora da Biblioteca Britânica, em artigo publicado no The Observer, alertou que é extremamente necessário que se crie um projeto para que sites e blogs sejam armazenados e catalogados, justamente por conta de sua brevidade. A proposta sugerida era induzir bibliotecários a fazer a seleção e organização do que deve ser arquivado (CARTA CAPITAL, 2009c).

Em 2007, a biblioteca britânica em parceria com o Arquivo Nacional e a Microsoft, tentou abrir arquivos guardados há um tempo, mas se surpreendeu ao perceber que os mesmos haviam se tornado obsoletos, pois não podiam ser mais lidos por máquinas modernas, por se tratarem de documentos com formatos antigos. A tentativa fracassada acabou por dar pontos aos documentos em papel, que podem ser lidos sem precisar de um aparato que os converta. A 
bibliotecária encerrou o artigo asseverando que o grande perigo, a seu ver, é a tecnologia criar um buraco negro para novos historiadores e escritores.

Em entrevista ao Programa Roda Viva em 2012, o historiador Robert Darnton quando questionado sobre a preservação da memória digital, destacou assim como Lynne Brindley, que não só o software e hardware se tornam obsoletos, mas os metadados também. Ou seja, para se achar o texto pretendido no ciberespaço é necessário que estes estejam atualizados, pois do contrário o texto desapareceria. Darnton destacou que na Universidade de Harvard havia uma enorme área para preservação do texto digital, no qual se migrava de um formato para o outro, a partir de uma espécie de olho eletrônico que fazia a leitura dos textos e armazenava em três dispositivos distintos. Mas a solução era temporária, pois, não se sabia até quando tal plano seria viável (RODA VIVA, 2012).

O historiador norte-americano também fez alusão ao engenheiro norte-americano de computadores Brewster Kahle, que fundou a Internet Archive em 1996 e que se dedica a manter arquivos de recursos multimídia utilizando para esse fim, a Wayback Machine. Tal sistema fotografa os websites e os arquiva em um banco de dados, o que possibilita ao usuário acessar as páginas capturadas. Segundo dados do site, em sua coleção estão elencadas 464 bilhões de páginas, que foram acessadas por mais de dois milhões e meio de usuários. A Internet Archive é uma organização sem fins lucrativos que teria sido criada para se tornar uma biblioteca da internet. Seus objetivos incluem a oferta de acesso permanente para pesquisadores, historiadores, estudantes, pessoas com deficiência, além do público em geral que se interessa por coleções históricas que existem em formato digital. O recebimento de doações ao longo dos anos ajudou a organização a crescer e a incluir outros tipos de arquivos como audios e vídeos.

A equipe da Internet Archive compara seu trabalho ao da Biblioteca de Alexandria, a maior do mundo antigo e que possuiria em seu acervo um exemplar de tudo aquilo que havia sido manuscrito no mundo até sua destruição por um incêndio. Segundo o programa da empresa, sem artefatos culturais, a civilização não tem memória e nenhum mecanismo para aprender com seus sucessos e fracassos. Por isso, a Internet Archive empenha-se em impedir que produtos derivados da internet desapareçam e, ao lado de instituições como a Library of Congress e o Smithsonian, "trabalham em preservar os registros para gerações futuras." 7 Sem dúvida, a iniciativa da empresa fundada por Kahle se constitui em um elemento importante para a preservação de páginas vinculadas na internet e que tendem a desaparecer ao longo do tempo. No entanto, ainda se espera que novos projetos no mesmo estilo sejam criados a fim de

${ }^{7}$ O programa completo do empreendimento pode ser consultado em: https://archive.org/about/ 
conseguir encontrar meios que garantam que no futuro, as páginas possam ser guardadas e preservadas assim como tem se feito com as informações em papel. É claro que algo do tipo não será realizado em um espaço curto de tempo, pois mais do que interesse em resguardar esse material, há outras implicações que incluem problemas com direitos autorais e mesmo quem poderá custear financeiramente o empreendimento.

A respeito das adversidades pelas quais os jornais vêm sendo acometidos, muitos grupos e proprietários dos impressos procuram se espelhar no exemplo do centenário The New York Times. Este também sofreu os efeitos da crise econômica de 2008 e viu sua queda em publicidade chegar a assustadores $64 \%$. O jornal então se reorganizou e tomou uma série de medidas que incluíram o chamado paywall, sistema que permite ao leitor degustar do conteúdo restrito antes de se tornar pagante. Outras práticas como a maior presença nas redes sociais, reportagens específicas para celulares e tablets, além de investimentos em nível internacional, também foram realizadas, o que levou a empresa a conseguir chegar atualmente num patamar de quase um milhão de assinantes digitais. Entretanto, nem todos aprovam a política do Times como o jornalista Jota Alcides, ex-editor do Jornal do Commercio, de Recife e do Correio Braziliense, de Brasília. Este acredita que tal conduta não resolverá o maior problema de todos que é a falta de atratividade dos conteúdos impressos. Na verdade, segundo Alcides, o efeito pode ser reverso fazendo com que o The New York Times conquiste mais leitores eletrônicos e, consequentemente, perca leitores do jornal impresso (ALCIDES, 2015).

Para finalizar, tentou-se nesse artigo fazer uma breve análise da situação da imprensa mediante o crescente avanço da internet. Para tal, foi preciso entender o jornal como fonte e objeto de pesquisa e perceber como o avanço da técnica e o surgimento de novos meios de produção, geraram debates que estão presentes nas obras literárias de diferentes épocas, nas memórias daqueles que trabalharam nas redações e no modo como os intelectuais analisaram seus aspectos positivos e negativos. Em seguida, se fez um balanço sobre a situação que a imprensa norte-americana e brasileira tem enfrentado, mediante o interesse cada vez mais pontual do leitor em relação à internet e as outras questões que ajudam a agravar a situação. Também se pontuou as soluções e conferências que as corporações jornalísticas vêm promovendo a fim de evitar o débâcle da mídia impressa. Não obstante, existem questões que precisam ser pensadas e debatidas, não só nos meios acadêmicos, mas pela sociedade como um todo, como por exemplo, o modo pelo qual será realizada a preservação daquilo que foi gerado pela internet, que extrapola o debate da imprensa e alcança outros domínios como os e-books, 
o conteúdo das redes sociais, os e-mails e até mesmo o risco de desaparecimento dos serviços postais tradicionais não discutidos nesse texto, mas não de menos importância. ${ }^{8}$

\section{Referências Bibliográficas}

ALCIDES, José. A Estratégia do The New York Times. In: Observatório da Imprensa, edição 855, 16 jun. 2015.

ARENDT, Hannah. A condição humana. Rio de Janeiro: Forense Universitária, 2001.

ARUGUETE, Natalia. Entrevista com Dênis de Moraes. Página/12, 24 fev. 2014. Disponível em: http://www.ihu.unisinos.br/noticias/528682. Acesso em: 10 mai. 2016.

BURKE, Peter. Uma historia social do conhecimento: de Gutenberg a Diderot. Rio de Janeiro: Zahar, 2003.

CALDAS, Álvaro. Deu no jornal: o jornalismo impresso na era da internet. Rio de Janeiro: Ed. PUC-Rio; São Paulo: Loyola, 2002.

CARTA Capital, n526, 17 dez. 2008a.

, n5520, 05 nov. $2008 b$.

, n526, 17 dez. 2008c.

, n536, 11 mar. 2009a.

, n559, 19 ago. $2009 \mathrm{~b}$.

,n531, 04 fev. 2009c.

, no555 22 jul. 2009d.

,nº66, 28 jul. 2010.

CASTILHO, Carlos. Crise leva jornais a rever projeto nos EUA. In: Observatório da Imprensa, 01 out.2005.

CHARTIER, Roger. A aventura do livro: do leitor ao navegador. São Paulo: Imprensa Oficial: Ed. Unesp, 1998.

\footnotetext{
${ }^{8}$ O correio da Suíça (Swiss Post) em parceria com a companhia Earth Class Mail passou a converter todas as correspondências para o formato digital. O usuário pode escolher o que quer receber fisicamente ao acessar a conta criada previamente ou ainda decidir o que pode ser descartado. Para que isso ocorra as duas empresas escaneiam os envelopes recebidos. O serviço também é valido para encomendas, já que o pacote é fotografado e o usuário decide seu destino final (CARTA CAPITAL, 2009d, p. 52-53).
} 
DARNTON, Robert. A questão dos livros: passado, presente e futuro. São Paulo: Companhia das Letras, 2010.

FOLHA de S. Paulo, 03 jul.2015. Disponível em http://www1.folha.uol.com.br/poder/2015/07/1651542-facebook-negocia-parcerias-comjornais-brasileiros.shtml. Acesso em: $13 \mathrm{dez} .2015$.

LÉVY, Pierre. A inteligência coletiva. São Paulo: Loyola, 2000.

LUCA, Tania Regina de. História dos, nos e por meio dos periódicos. In: PINSKY, Carla (org). Fontes históricas. $2^{\mathrm{a}}$ ed. São Paulo: Contexto, 2006.

MORAES, Dênis (org.), RAMONET, Ignacio, SERRANO, Pascual. Mídia, Poder $e$ Contrapoder. São Paulo: Boitempo; Rio de Janeiro: FAPERJ, 2013.

NAPOLITANO, Marcos. A história depois do papel. In: PINSKY, Carla (org). . OBSERVATÓRIO da Imprensa. Jornais protestam contra ferramentas de busca. Edição 366, 01 fev. 2006.

O Estado de S. Paulo, 03 mai. 2015.

PIMENTA, Angela. Há luz no fim do túnel dos jornais impressos? In: Observatório da Imprensa. Edição 858, 09 jul. 2015.

RODA VIVA. Entrevista Robert Darnton. São Paulo, Televisão Cultura, 24 set. 2012.

SERRA, Liliana Giusti. Livro Digital e bibliotecas. Rio de Janeiro: FGV, 2014.

SILVA, Marcelo Soares da. O computador no jornalismo brasileiro. Disponível em: http://www.saladeprensa.org/art740.htm. Acesso em: 26 jul. 2010.

SUSSEKIND, Flora. Cinematógrafo de Letras: literatura, técnica e modernização no Brasil. São Paulo: Companhia das Letras, 1987.

VIEIRA, Lívia de Souza. Parâmetros éticos para uma política de correção de erros no jornalismo online. Dissertação (mestrado) - Universidade Federal de Santa Catarina, Centro de Comunicação e Expressão, Programa de Pós-Graduação em Jornalismo, Florianópolis, 2014.

VIRILIO, Paul. Guerra e Cinema. São Paulo: Scritta, 1984.

ARTIGO ENVIADO EM: 23/02/2016

ARTIGO ACEITO PARA PUBLICAÇÃO EM: 01/06/2016 